\title{
Thai Consumers Willingness to Pay for Food Products with Geographical Indications
}

\author{
Pimsiri Seetisarn \\ Master of Business Administration, Mahidol University International College \\ 999 Buhhamonthon 4 Road, Salaya, Nakhonpathom, 73170, Thailand \\ Tel: 66-(0)2679-5053Ｅ-mail: icmba@mahidol.ac.th \\ Yingyot Chiaravutthi (Corresponding author) \\ Business Administration Division, Mahidol University International College \\ 999 Buhhamonthon 4 Road, Salaya, Nakhonpathom, 73170, Thailand \\ Tel: 66-(0)2441-5090Ｅ-mail: icyingyot@mahidol.ac.th
}

Received: March 9, 2011 Accepted: April 7, 2011 doi:10.5539/ibr.v4n3p161

This research is funded by Mahidol University International College's Seed Grant. We would like to thank Mrs. Sawitree Pitchayachai who gave us her full support in conducting experiments at Mahidol University, Salaya.

\begin{abstract}
Geographical Indication (GI) is a name, or sign, that refers to a specific characteristic of geographical location or origin. GI is used to both protect and guarantee that the product has a unique characteristic, resulting from being qualifiedly produced in a specific place. There are many products in Thailand that have been certified by the Ministry of Commerce, carrying the GI label. The purpose of conducting this research is to study Thai consumers' willingness to pay (WTP) for products with GI labels. This experiment was carried out under the $n$th price auction method on Doi Tung coffee, Tung Kula Ronghai Thai Hom Mali rice, and Chaiya salted eggs. Sixty participants were asked to offer bids for three products each with different types of labels, a normal label; a label stating the product's origin; and a label which stated the product's origin and contained a GI sign. The results show that Thai consumers' WTPs are influenced by the origin of the product. However, the WTPs of GI labels do not significantly differ from the WTPs of labels which state the product's origin. This implies that Thai consumers value the product's origin, but do not recognize the importance of the GI label.
\end{abstract}

Keywords: Geographical Indication, Food Label, $n$th Price Auction, Willingness to Pay

\section{Introduction}

Geographical Indication is a name or sign that refers to a specific characteristic of geographical location or origin, such as a town, region, or country. Examples are Champagne, which is the name of a wine production region in the far north of France; Scotch whisky or Scotch, is whisky which is produced in Scotland; and a dry-cured ham from the Parma region, Italy is called Parma ham. GIs are also used as a means of certifying that the products are renowned for the quality, reputation and characteristic of goods in particular areas (Park \& Yanos, 2006). This also illustrates that the geographical location of products contain specific local factors which have a direct impact on the product's quality.

Different GI protection systems exist between one country and another. In the European Community, the system is very strong, due to its many years of development and progress. There are more than 2,000 GI products; 1,400 being wines and spirits and 600 being other products registered in Brussels, Belgium, with the added advantage that these products are protected in all of the other EU member countries (Kulkumthorn, 2006).

To expand Thai GI products in the global market, the Department of Intellectual Property applied to register one of its products, Tung Kula Ronghai Thai Hom Mali Rice, in the EU on April 28th 2006. The Department of Intellectual Property expects that the registration request will be approved during January 2011 (Thailand Press Release, 2010). Two more Thai products, Doi Tung and Doi Chang coffee have just recently been submitted for registration by the Department of Intellectual Property as well. 
GI registration creates pride for agriculturists in their locally made products, and deters them from migrating from their place of origin. Furthermore, the value of products with GI labels will increase once they are viewed as premium grade products. This was highlighted by the Director General of Thailand's Department of Intellectual Property at the regional GI conference, on June 11th in Bangkok. Certain agricultural products in Thailand with GI status have witnessed 20\% to 30\% price increases (Tunsarawuth, 2009). For example, the price of Sangyod rice has increased from 40 to 60 baht per kilogram since it was registered as a GI product (Food Industry Thailand, n.d.).

Since GI is considered to be fairly new to most consumers in Thailand, the main purpose of this paper is to study Thai consumers' behavior, particularly their demand for food products with GI labels. The results certainly have policy implications. In addition, GI involves a development in the production system, and many parties will benefit from this development including the producers, consumers, and the country.

\section{Literature Review}

With rising consumer demand for high-quality food, the GI label plays an important role for both governments and producers. The EU, in particular, initiated protected GI labels in order to preserve local products' niche markets and raise their competitiveness; whilst producers, on the other hand, could adopt GI labels as a differentiation strategy (McCluskey \& Loureiro, 2003). As such, a product with a GI label guarantees consumers that the product is special and allows producers to command a price premium. Loureiro \& McCluskey (2000) cite the GI label's success on its ability to signal high quality, its ability to alter consumers' perceptions regarding the collective reputation of the product, and the country-of-origin benefits. The high-quality signal is essential since a "special" flavor can only be verified after consumption, therefore, a GI label could reduce asymmetric information problems between producers and consumers. Bordeaux wine is one of the many examples that illustrate how a collective reputation affects consumers' perception and the product's pricing (Landon \& Smith, 1998). As for the country-of-origin effects, several marketing studies have confirmed its relationship to consumers' perceptions and price premiums.

Many previous studies on the topic of how origin related labels affect consumers' willingness to pay have been conducted using several methods. Fotopoulos \& Krystallis (2003) conducted both qualitative and quantitative surveys on consumer's willingness to pay for Zagora apples from Central Greece. The quality label used in the survey was a Protected Denomination of Origin (PDO) label, to determine whether the label, or the price of the apples, had more influence on the purchasing decisions of the buyers. After performing both Conjoint and Cluster analysis, the results show that consumers' buying decisions are mostly based on the quality label rather than the price. Nonetheless, the results also implied that the existence of a PDO label is more important than the product's price for only discrete segments of buyers, who are mostly upper social and income groups. It can be concluded that extensive promotional campaigns would be required in order to use the PDO label as an effective marketing strategy.

Menapace et al. (2008) conducted a study on the impact on Canadian consumers, of a country-of-origin label (COOL) and a GI label applied to extra virgin olive oil. COOL specifies the country in which the product is produced; whilst the GI label focuses on a city or region within that country; for which the producer must comply with certain requirements. The method of this survey was face-to-face interviews in which the qualified participants had to be screened first. The results show that products, such as extra virgin olive oil, with both COOL and GI labels were seen as high quality, value-added products. On the other hand, when a comparison was made of consumers' preferences, COOL labels are proved to influence Canadians more than the GI labels.

Further research on Hessian apple wine was conducted by Teuber (2009) regarding the expectations of consumers and producers towards GI labels. Both online-surveys and in-depth interviews were conducted on Hessian consumers and one of the leading producers of Hessian apple wine. Results from over $70 \%$ of 741 consumers show that the GI label supports the local producers and secures their traditional cultural assets. However, from the producer's point of view, the best advantage of having GI is that it ensures the quality of Hessian apple wine against false claims by other competitors. In addition, $48 \%$ of all consumers were willing to pay more for Hessian apple wine with GI. However, the results also show that awareness and knowledge about GI amongst Hessian consumers is still very limited. This conclusion is supported in that only $6.8 \%$ of 741 consumers claimed to know at least one label out of the two labels, the PDO label and the PGI label, from the online-survey.

There are several researches that have adopted the Hedonic model to quantify WTP. One study, relating to the affect of region of origin on the product price, focused on empirical evidence of Café de Marcala. The objective was to study the relevance of regional reputation in the coffee market by using a Hedonic pricing model to represent results for Honduran coffee. According to the study, the results show that coffee from Guatemala achieves high price premiums due to its well-established reputation, whereas Honduran coffees are discounted because of their coffee origins. The conclusion was that, currently, Honduran coffee growers cannot influence the coffee price regarding the 
reputation of its product, but should rather try to influence it in terms of their coffee's qualities (Teuber, 2008).

Another study regarding the efficiency of the use of labels on product quality was undertaken by Loureiro \& McClusky (2000). A survey and a Hedonic price model were utilized to calculate consumer's willingness to pay for Spanish meat and Galician veal, with Protected Geographical Indication (PGI) label's attached. It was found that if a PGI label is applied to high quality cuts of meat, it increases their value to premium levels of quality. On the other hand, applying PGI labels on normal or low quality products would not be an effective marketing strategy, and is more likely to damage the collective reputation of the products. Moreover, PGI labels will not have any effect on extremely high-end products, whose collective reputation is always higher than the PGI reputation.

Loureiro \& McClusky (2000) argued that "If the country-of-origin influences the market for PGI products, then the success of many products will already be conditioned by the location of the production. Thus, there are many factors in addition to quality of the product that make the PGI label successful". In the European market, most research has reviewed the importance of the special characteristics of regional products; this has lead to the creation of studies on the economic consequences of PGI and PDO products.

Very little research has been conducted on GI labels outside the EU. However, in the US, several studies have focused on the "state" label instead. Examples include Adelaja et al. (1990) and Govindasamy et al. (1998) on the New Jersey Fresh label; Patterson et al. (1999) on the Arizona Grown label; and Quagrainie et al. (2003) on the Washington Apple label. As for the Thailand market, to our knowledge, no research has been conducted to find consumers' demand and willingness to pay for PGI/PDO products. As such, this will be a good opportunity to ascertain how quality labeling strategies could impact Thai consumers' perceptions, and their buying decisions.

\section{Research Methodology}

This study was conducted with a sample size of 60 , and the participants were selected after advertisements were posted around Mahidol University and the Salaya area. All of the participants were equally allocated into 6 sessions, with 10 participants per session, in order to obtain a variety of willingness to pay for food with "normal" labels, "origin" labels, and "GI" labels from a total of 5 auction rounds.

On the day of the experiment, firstly, participants were given 500 Baht and seated in a closed room. Each participant had to randomly select an ID, running alphabetically from A to J, in order to hide their real identity. The experimenter then explained to all participants the method of the random $n$ th-price auction, and the procedures to be conducted during the experiment. The random $n$ th-price auction is designed to elicit WTP, which provide a better result with off-margin bidders (Shogren et al., 2001). The procedures were similar to the experiment conducted by VanWechel et al. (2003), Huffman et al. (2003), Rousu et al. (2004), and Chiaravutthi (2011). The auctions consisted of 5 rounds, which were 2 training rounds, and 3 actual bidding rounds. Table 1 shows the sequence of the experimental session.

The auction methodology has several advantages over the others in eliciting consumers' WTP (Noussair et al., 2004). Firstly, money is used by all participants as a means of quantifying their preferences. Secondly, participants are committed to purchasing the product, and in some cases, consuming it. Thirdly, participants' dominant strategy during the auction is to bid according to his/her true valuation. Fourthly, participants must consider all of the characteristics of the products, including the origin and the GI sign prior to the bidding decision.

Table 1 explains the sequences of the experiment, and describes the three different labels used. The "Normal" label, which was used in the first actual round, provides details of the product's type, general instructions, weight, and the expiration date. The "Origin" label, which was used in the second actual round, consists of the product's type, general instructions, weight, expiration date, and the product's origin. Origin, in this sense, means the place where the product was produced. Lastly, the "GI" label, which was used in the third actual round, consists of the product's type, general instructions, weight, expiration date, the product's origin and the GI sign, which is the logo certified by the Department of Intellectual Property.

For the first training round, only a bag of sugar was offered in order to get the participants to understand the bidding process. The number of testing products was then increased in the second round to three, namely, a bag of salt, sun-dried banana, and sweet tamarind. Both training rounds were carried out to allow the participants to become familiar with the $n$th price auction. In the first training round a bag of sugar was shown to the participants for bidding, and they were allowed 5 to 10 minutes to submit their bids on a piece of paper, which they then put in an envelope and sealed. The experimenter then opened all the envelopes and wrote all the bids on the board, ranking them from the highest down to the lowest. A decision number from 2 to 10 was then randomly selected. The participants who offered bids between the highest to least highest than that of the decision number were the winners, and had to buy the bag of sugar at the same price as the decision number. The second training round was carried out 
in the same way as the first round, the participants were asked to bid for a bag of salt, sun-dried banana, and sweet tamarind (all without GI labels). The participants were asked if they had any questions, following which the experiment commenced.

After the training rounds were completed, the 6 experimental sessions were split into 2 sessions. For the first 3 sessions, the actual bidding commenced immediately after the training rounds. On the other hand, in the other 3 sessions the participants were given a document providing information about Geographical Indication (GI). Participants were allowed approximately 10 minutes to read and digest the information on GI before continuing to the actual rounds.

The three types of food for the actual rounds consisted of Doi Tung coffee, Tung Kula Ronghai jasmine rice, and Chaiya salted eggs which had already been registered for GI in Thailand. However, all of their advertising packaging and labels were removed and were replaced with new packaging and artificial labels which stated only the product's type, weight, and origins of the food as shown in Figure 1.

The participants who offered the highest to least highest bids than the decision number were the winners. One out of the five rounds was randomly selected as being binding. The winners used the 500 Baht given at the beginning of the experiment, to buy the food at the price offered in that round. This means that only the winners in that binding round had to purchase the product item, using their endowed money. All three actual rounds were randomly arranged to prevent any sequential effects.

After the experimental auctions, all the participants were asked to fill in questionnaires about their personal information, their perspectives toward products with Geographical Indication, background knowledge, and shopping behavior. Moreover, the participants were asked for their attitudes towards the importance of products' origins, their frequency of label checking before purchasing, and their knowledge about GI.

The 60 participants comprised of 12 males and 48 females. The average age of all participants was 32.88 years old, with $93 \%$ of them having a Bachelor's Degree or higher. The majority of participants have a monthly income in the range of 10,000 to $50,000 \mathrm{Baht}, 95 \%$ of them have a permanent employment, and the average number of members in the household is 4.38 people. The average score regarding the importance of the product's origin is 3.45 (where 5 $=$ extremely important and $1=$ not important), which shows that participants view the origin of the products as quite important. Additionally, with the average score of 4.10 (where $5=$ every time and $1=$ never) on whether they consider the label prior to purchase, means that they usually read the food label before making a purchasing decision. The average rate for understanding GI is only 2.38 (where $5=$ fully understand and $1=$ do not understand), which is considered to be low since GI is an international practice and has been promoted by the Thai government for several years. This implies that information about GI has not been communicated effectively to Thai consumers. It should be noted that regressions were carreid out to find the relationships between bid price, and demographic and attitudinal variables. However, partly, due to the small sample size, the results are mostly insignificant; and can be ignored.

\section{Results and Analysis}

Focusing on the consumers' Willingness To Pay (WTP) for each product, the average bid for origin labels and GI labels are higher than the average bid for normal labels. For example, there is an increase in the average bid from 46.57 Baht in the first round of the coffee auction, to 55.50 Baht in the second round, and to 56.87 Baht in the third round; which equates to a premium of $19.18 \%$ and $22.12 \%$ respectively as shown in Table 2 . This trend also applies to jasmine rice and salted eggs, which show an increase of $6.77 \%$ and $17.45 \%$ respectively. Nevertheless, there is no significant increase when comparing the average bids of the three products in the second and the third rounds.

In addition, t-test statistics were carried out to ascertain the differences between average bids for the normal label, the origin label, and the GI label. As shown in Table 3, the p-value for comparisons between normal and GI labels of all products is lower than 0.05 . This indicates that the average bids between products with normal and GI labels are significantly different. From this result, it seems that all of the participants' WTPs were significantly influenced by the GI sign. However, in fact, the origin of each product was also printed on the label together with the GI sign. Hence, at this moment, there is no confirmation that the GI sign or the GI label can create an influence on participants' WTP. The reasons to support this argument are that in comparisons between the origin and GI labels of each product, the p-value from a comparison amongst the three products resulted in 0.022 , a p-value of 0.185 for coffee and 0.365 for salted eggs which indicates that there is no considerable difference in consumers' WTP for these two products. Unlike the results of jasmine rice, the null hypothesis is rejected at a p-value of 0.003 . It can be concluded that the GI sign has an influence on consumers' WTP only for jasmine rice.

In order to have a clearer view of the trend of consumers' WTP on different types of products, the results of the 
experiment are summarized and presented in Figure 2. As shown in Figure 2, there are similar increasing trends in the average bids for coffee, jasmine rice, and salted eggs from the first to the third rounds. This means that consumers are willing to pay for products whose sources of origin are well-known, even if there is no difference in the products' physical appearance.

When comparing the premium percentage between the first and the third rounds, coffee had the highest percentage of $22.12 \%$, salted eggs $19.27 \%$, and jasmine rice $10.29 \%$. It can be implied that participants involved in this experiment have a higher perception of the GI label for coffee than they do for jasmine rice and salted eggs. Nevertheless, it does not mean that these differences can also be fully applied to different experimental groups since participants in various geographical areas might not have the same perceptions of the three products.

In order to study how GI information could affect consumers' WTP, participants in the experiment were divided into two main groups, one group without any GI information being given, and a group given GI information after the second training round. The results of the average bidding from these two experimental groups are shown in Tables 4 and 5 .

The results show that there is the same pattern of increase in the average bids between the two groups. With a premium of $16.44 \%$ and $19.43 \%$ from the first group and $13.42 \%$ and $16.08 \%$ from the second group; it implies that the information given about GI has no influence on the participants' WTP, since the premium percentage from the second group is actually lower than the first one. Moreover, both the average bids and maximum bids from each round of the first group are also higher than those from the second group, even though this resulted in a significant reduction of the standard deviation. In order to support the prior conclusion, t-test statistics and $p$-value analysis were also used to seek out any differences between these two experimental groups as shown in Table 6 .

As a result, the p-value of 0.439 for coffee, 0.479 for jasmine rice, and 0.419 for salted eggs, from the analysis are all higher than 0.05 . Hence, the null hypothesis of no difference between the average bids of the two groups is not rejected. This confirms that there is no difference between average bids from participants who were and were not given GI information.

\section{Conclusions and Recommendations}

In this experiment exploring consumers' WTP for three kinds of food products, conducted with a total 60 participants over six sessions, participants took part in auctions for a total of 9 rounds, for 3 products; each with 3 different types of label, a normal label, a normal label with the origin of the product (origin label), and a normal label with both the origin of the product and a GI sign (GI label). From a total of 180 bids, $55.56 \%$ of all participants were willing to pay more for the products with origin labels, compared to those with normal labels. The premium can be calculated at $15.37 \%$, as the average bid for the product with the label of origin is $34.61 \mathrm{Baht}$, whilst the average bid for the product with the normal label is 30 Baht.

The same trend of increase can be seen from a comparison between products with normal labels and those with GI labels. The results show that $65 \%$ of participants were willing to pay more for products with GI labels, than those with normal labels. This could imply that the majority of consumers view the origin of the products as one of the key indicators affecting their purchasing decision. However, this is difficult to confirm as the origin of the product is also printed on the GI label.

Additionally, there was no significant premium percentage difference between the average bid for GI labels and the average bid for origin labels, since $59.44 \%$ of all participants bid the same price for both of these. Further research could be conducted to ascertain if any product would cause consumers to pay a different price for these 2 labels. Out of the 3 products, jasmine rice was the only product that resulted in a p-value of lower than 0.05 . This means that consumers are willing to pay a different price for jasmine rice with a label of origin, than they would for a GI label.

Similar to existing literature, a conclusion can be drawn that the origins of the products are important, and obviously affect consumers' WTP. But price premiums found in previous studies usually vary depending on the products, countries, and methodologies. As for the GI label, Thai consumers do not regard GI labels differently from labels that indicate the place of production, similar to Bonnet \& Simioni (2001) who found that French consumers do not value GI labels.

It is a common assumption that Thai consumers usually put a higher valuation on imported food, especially from developed countries; whilst food produced in rural Thailand usually generates an image of lower quality. The results here, on the contrary, show that certain geographical locations in Thailand are perceived by consumers as delivering high quality products. However, the low premium for Tung Kula Ronghai rice can be explained by the fact that rice appears in almost all Thai meals. As such, consumers may not be willing to pay higher prices for their daily meal. Salted eggs, on the other hand, are usually a side dish. In the past, Chaiya salted eggs were considered a premium 
gift when Thais traveled through Chaiya province, so the fact that it carries a high premium is not surprising. However, Chaiya salted eggs are currently becoming available in major supermarkets around the capital city, which could diminish its valuation. As for coffee, due to the fact that international coffee chains are available in Thailand at almost every prime location, the fact that Thai's Doi Tung coffee receives such recognition is certainly encouraging to local producers.

Moreover, the results of the percentage premiums amongst the three types of product show that the percentage premium for the GI label compared to the normal label significantly increases; $22.12 \%$ for coffee, $10.29 \%$ for Jasmine rice, and $19.27 \%$ for salted eggs. This implies that consumers value the product that indicates both the origin and also the GI compared to the products that have a normal label or a label of origin. This percentage premium could help producers when setting up their prices. In the market, Jasmine rice is priced at around 35 Baht per kilogram, compared to Tung Kula Ronghai jasmine rice which is 45 Baht per kilogram. The percentage premium of Tung Kula Ronghai jasmine rice is 30\% higher. Compared to the WTP premium of $10.29 \%$ in this study, GI rice would be considered over-priced. GI labeled salted eggs, also has the same pricing trend, five Chaiya salted eggs' are priced at 50 Baht, $25 \%$ higher than other salted eggs without GI. Coffee is another example, looking at 200 grams of Espresso Roasted coffee, DoiTung coffee when compared to other brands has a percentage premium of $70 \%$, based on its price of 230 Baht.

Although the cost of production of GI products is not considered here, it is obvious that GI producers have set prices far exceeding consumers' WTP. Therefore, GI producers should adjust their prices according to consumers' WTP. Another negative implication for GI producers is that producers whose products come from the same geographical location, could also command a premium similar to GI producers. This means that there is an incentive for producers to falsely claim that their products are produced from a specified location; therefore avoid GI registration with the Ministry of Commerce. However, the benefits in terms of intellectual property protection could justify legal registration and the obtaining of an official GI label.

In order to study how GI information could affect consumers' WTP, it had to be ensured that none of the people involved in the experiment would have had any information about GI beforehand. However, half of the participants were given a document relating to information of Geographical Indication before starting the first round. After an analysis, however, the p-value obtained from statistical analysis implies that participants had stronger preferences towards the origin label than the GI label. In other words, there is no difference for consumers' WTP between consumers who were given GI information and those who were not.

It would seem that Thai consumers are still not aware of the difference between the origin of products and their Geographical Indication. Therefore, GI information and its benefits to all producers and consumers should be broadcast and distributed widely. However, before the monetary benefits are confirmed, the Thai government should focus on the protection of GI producers' intellectual property rights. For example, during March 2011, the Department of Intellectual Property has issued a warning of intellectual property violation against sellers who claimed to sell their rose-apples as "Chompu Phet Sairung" which is the Phetchaburi province's famous fruit and has registered for the GI since 2008 (Thailand Press Release, 2011). At the same time, the government sector should also carry out further research and analysis, in order to provide supporting information to the private sector and individuals about local products which could be registered for GI. Moreover, once the local products have been registered locally, the government sector should lead the way in encouraging the private sector to register, and promote Thai local products so that they become well-established both in and outside the country, in the same way as Parmesan cheese and Parma ham has been promoted by Italy, or Bordeaux wine by France. If successful, geographical indication would definitely be a major competitive advantage in creating the country's identity, enhance the country's pride, and reputation in today's highly aggressive world market.

\section{References}

Adelaja, A. O., Brumfield, R. G., \& Lininger, K. (1990). Product differentiation and state promotion of farm produce: An analysis of the Jersey fresh tomato. Journal of Food Distribution 21(3), 73-85.

Bonnet, C., \& Simioni, M. (2001). Assessing consumer response to protected designation of origin labeling: a mixed multinomial logit approach. European Review of AgriculturalEconomics 28 (4), 433-449, doi:10.1093/erae/28.4.433, http://dx.doi.org/10.1093/erae/28.4.433

Chiaravutthi, Y. (2011). Consumer willingness to pay and implications of differing GM labeling policy, working paper.

Food Industry Thailand. (n.d.). GI: A sign of open door policy for Thai export goods. [Online] Available: http://www.foodindustrythailand.com (March 6, 2010). 
Fotopoulos, C., \& Krystallis, A. (2003). Quality labels as a marketing advantage - The case of the "PDO Zagora" apples in the Greek market. European Journal of Marketing 37(10), 1350-1374, doi:10.1108/03090560310487149, http://dx.doi.org/10.1108/03090560310487149

Govindasamy, R., Italia, J., \& Thatch, D. (1998). Consumer awareness of state-sponsored marketing programs: An evaluation of the Jersey fresh program. Journal of Food Distribution Research 29(3), 7-15.

Huffman, W. E., Shogren, J. F., Rousu, M., \& Tegene, A. (2003). Consumer willingness to pay for genetically modified food labels in a market with diverse information: Evidence from experimental auctions. Journal of Agricultural and Resource Economics 28(3), 481-502.

Landon, S., \& Smith, C. E. (1998). Quality expectations, reputation, and price. Southern Economic Journal 64, 628-647, doi:10.2307/1060783, http://dx.doi.org/10.2307/1060783

Loureiro, M. L., \& McCluskey, J. J. (2000). Assessing consumer response to protected geographical identification labeling. Agribusiness 16(3), 309-320, doi:10.1002/1520-6297(200022)16:3<309::AID-AGR4>3.0.CO;2-G, http://dx.doi.org/10.1002/1520-6297(200022)16:3<309::AID-AGR4>3.0.CO;2-G

McCluskey, J. J., \& Loureiro, M. L. (2003). Consumer preferences and willingness to pay for food labeling: A discussion of empirical studies. Journal of Food Distribution Research 34(3), 95-102.

Menapace, L., Colson, G., Grebitus, C., \& Facendola, M. (2008). Consumer preferences for extra virgin olive oil with country-of-origin and geographical indication labels in Canada. Presented at the American Agricultural Economics Association Annual Meeting, 27-29 July 2008, Orlando, FL.

Noussair, C., Robin, S., \& Ruffieux, B. (2004). Do consumers really refuse to buy genetically modified food? The Economic Journal 114, 102-120, doi:10.1046/j.0013-0133.2003.00179.x, http://dx.doi.org/10.1046/j.0013-0133.2003.00179.x

Park, W. W., \& Yanos, A. A. (2006). Treaty obligations and national law: Emerging conflicts in international arbitration. Hastings Law Jounal 58, 251.

Quagrainie, K. K., McCluskey, J. J., \& Loureiro, M. L. (2003). A latent structure approach to measuring reputation. Southern Economic Journal 67(4), 966-977, doi:10.2307/1061661, http://dx.doi.org/10.2307/1061661

Rousu, M., Huffman, W. E., Shogren, J. F., \& Tegene, A. (2004). Are United States consumers tolerant of genetically modified foods? Review of Agricultural Economics 26(1), 19-31, doi:10.1111/j.1467-9353.2003.00159.x, http://dx.doi.org/10.1111/j.1467-9353.2003.00159.x

Shogren, J. F., Margolis, M., Koo, C., \& List, J. A. (2001). A random $n$ th-price auction. Journal of Economic Behavior \& Organization 46, 409-421, doi:10.1016/S0167-2681(01)00165-2, http://dx.doi.org/10.1016/S0167-2681(01)00165-2

Teuber, R. (2008). Geographical Indications and the value of reputation - Empirical evidence for Cafe de Marcala. Presented at 12th Congress of EAAE (European Association of Agricultural Economists) 26-29 August 2008, Ghent, Belgium.

Teuber, R. (2009). Producers' and consumers' expectations toward geographical indications - empirical evidence for Hessian apple wine. Presented at $113^{\text {th }}$ EAAE Seminar, 3-6 September 2009, Crete, Greece.

Thailand Press Release. (2010). The Department of Intellectual Property moves forward in pushing GI into the EU, and reveals the way out of PWL. [Online] Available: http://www.thaipr.net/nc/readnews.aspx?newsid=E29BCA48F1364E161A96FE228EF8F07A (June 4, 2010).

Thailand Press Release. (2011). The Department of Intellectual Property warns consumers: beware of claimed ““'Chompu Phet Sairung," GI product from Phetchaburi province. [Online] Available: http://www.thaipr.net/nc/readnews.aspx?sec=\&newsid=046990EA89AC4BD7FF5DE79BBC366AE1 (March 9, 2011).

Tunsarawuth S. (2009). EU says GI products would benefit Asian poor in renewing IP Assistance. [Online] Available: http://www.ip-watch.org/weblog/2009/06/12/eu-says-gi-products-would-benefitasian-poor-in-renewing-ip-assistance/ (March 6, 2010).

VanWechel, T., Wachenheim, C. J., Schuck, E., \& Lambert, D. K. (2003). Consumer valuation of genetically modified foods and the effect of information bias. Agribusiness and Applied Economics Report No. 513, Department of Agribusiness and Applied Economics, North Dakota State University. 
Table 1. Sequences of the experimental session

\begin{tabular}{|ll|}
\hline Round & Description \\
\hline Training Round 1 & Auction for a bag of sugar \\
Training Round 2 & Auction for a bag of salt, sun-dried banana, and sweet tamarind \\
Actual Round 1 & Auctions for three types of food with "Normal" labels \\
Actual Round 2 & Auctions for three types of food with labels that show the origin of the food, ("Origin" labels) \\
& Auctions for three types of food with labels that show the origin of the food and the Geographical \\
Actual Round 3 & Indication (GI), ("GI" labels) \\
\hline
\end{tabular}

Table 2. Comparisons between consumers' WTP amongst the three products

\begin{tabular}{|lll|}
\hline Coffee & Average bid in Baht [SD] & \% Premium from Normal label \\
\hline Coffee with a Normal label & 46.57 & N/A \\
& {$[34.43]$} & \\
Coffee with an Origin label & 55.50 & $19.18 \%$ \\
& {$[44.94]$} & \\
Coffee with a GI label & 56.87 & $22.12 \%$ \\
& {$[45.50]$} & \\
\hline
\end{tabular}

\begin{tabular}{|lll|}
\hline Jasmine Rice & Average bid in Baht [SD] & \% Premium from Normal label \\
\hline Jasmine rice with a Normal label & 25.10 & N/A \\
& {$[10.35]$} & \\
Jasmine rice with an Origin label & 26.80 & $6.77 \%$ \\
& {$[10.07]$} & \\
Jasmine rice with a GI label & 27.68 & $10.29 \%$ \\
& {$[10.08]$} & \\
\hline
\end{tabular}

\begin{tabular}{|lll|}
\hline Salted eggs & Average bid in Baht [SD] & \% Premium from Normal label \\
\hline Salted eggs with a Normal label & 18.33 & N/A \\
& {$[7.76]$} & \\
Salted eggs with an Origin label & 21.53 & $17.45 \%$ \\
& {$[8.25]$} & \\
Salted eggs with a GI label & 21.87 & $19.27 \%$ \\
& {$[8.45]$} & \\
\hline
\end{tabular}

Table 3. t-Test statistics for different labels of all types of products

\begin{tabular}{|llcc|}
\hline Product & Label comparisons & t-Statistics & p-value \\
\hline All products & Normal label and Origin label & 4.500 & $0.000^{* *}$ \\
& Normal label and GI label & 5.359 & $0.000^{* *}$ \\
& Origin label and GI label & 2.313 & $0.022^{*}$ \\
Coffee & & & $0.002^{* *}$ \\
& Normal label and Origin label & 3.182 & $0.000^{* *}$ \\
& Normal label and GI label & 3.720 & 0.185 \\
Origin label and GI label & 1.342 & 0.060 \\
Jasmine rice & & & $0.004^{* *}$ \\
& Normal label and Origin label & 1.920 & $0.003^{* *}$ \\
Nalted eggs & Origin label and GI label & 2.995 & $0.000^{* *}$ \\
& & 3.075 & $0.000^{* *}$ \\
\hline
\end{tabular}

Note: $*$ p-valve $<0.05,{ }^{* *}$ p-value $<0.01$. 
Table 4. Average bids from participants without GI information

\begin{tabular}{|lllll|}
\hline Label Types & MAX & MIN & Average bid in Baht [SD] & \% Premium \\
\hline Normal label & 160 & 0 & 38.72 & N/A \\
& & & {$[30.98]$} & $16.44 \%$ \\
Origin label & 250 & 0 & 45.09 & $19.43 \%$ \\
& & & {$[39.94]$} & \\
GI label & 230 & 0 & 46.24 & {$[40.44]$} \\
\end{tabular}

Table 5. Average bids from participants given GI information

\begin{tabular}{|lllll|}
\hline Label Types & MAX & MIN & Average bid in Baht [SD] & \% Premium \\
\hline Normal label & 50 & 0 & 21.28 & N/A \\
& & & {$[8.75]$} & $13.42 \%$ \\
Origin label & 60 & 5 & 24.13 & $16.08 \%$ \\
& & & {$[9.2]$} & \\
GI label & \multirow{2}{*}{65} & 0 & 24.70 & {$[9.58]$} \\
\end{tabular}

Table 6. t-Test statistics of participants with and without GI information

\begin{tabular}{|lll|}
\hline Type of product & t-Statistics & p-value \\
\hline Coffee & 0.780 & 0.439 \\
Jasmine rice & 0.712 & 0.479 \\
Salted eggs & 0.815 & 0.419 \\
\hline
\end{tabular}

\section{Actual Round 1}

\begin{tabular}{|c|c|c|}
\hline Coffee Beans & Jasmine Rice & Salted Eggs \\
\hline $\begin{array}{l}\text { Dark Roasted Coffee Beans } \\
\text { General instructions } \\
\text { for coffee making: } \\
\text { - Coffee should be brewed in } \\
\text { water heatedto a temperature } \\
\text { between } 90-96^{\circ} \mathrm{C} \text { for } 4-5 \\
\text { minutes. } \\
\text { - It is recommendedto use } 2 \\
\text { tablespoons ( } 10 \mathrm{~g} \text {.) of coffee } \\
\text { per } 180 \mathrm{ml} \text { of filtered water }\end{array}$ & Jasmine Rice $100 \%$ & $\begin{array}{l}\text { Salted eggs no. } 1 \\
\text { Net content } 4 \text { pcs. }\end{array}$ \\
\hline $\begin{array}{l}\text { net weight: } 200 \text { gram } \\
\text { EXP: } 11 / 06 / 11\end{array}$ & $\begin{array}{l}\text { net weight: } 1 \text { kilogram } \\
\text { EXP: } 29 / 06 / 11\end{array}$ & $\begin{array}{l}\text { net weight: } 65-70 \text { gram } / \text { pc. } \\
\text { EXP: } 29 / 12 / 10\end{array}$ \\
\hline
\end{tabular}




\section{Actual Round 2}

\begin{tabular}{|c|c|c|}
\hline $\begin{array}{l}\text { DoiTung Coffee Beans } \\
\text { DoiTung Dark Roasted } \\
\text { Coffee Beans }\end{array}$ & $\begin{array}{l}\text { Tung Kula Ronghai } \\
\text { Jasmine Rice } \\
\text { Tung Kula Ronghai } \\
\text { Jasmine Rice } 100 \%\end{array}$ & $\begin{array}{l}\text { Chaiva Salted Eggs } \\
\text { Chaiya Salted eggs no. } 1 \\
\text { Net content } 4 \text { pcs. }\end{array}$ \\
\hline $\begin{array}{l}\text { General instructions } \\
\text { for coffee making: } \\
\text { - Coffee should be brewed in } \\
\text { water heated to a temperature } \\
\text { between } 90-96^{\circ} \mathrm{C} \text { for } 4-5 \\
\text { minutes. } \\
\text { - It is recommendedto use } 2 \\
\text { tablespoons }(10 \mathrm{~g} \text {.) of coffee } \\
\text { per } 180 \mathrm{ml} \text { of filtered water }\end{array}$ & & \\
\hline $\begin{array}{l}\text { net weight: } 200 \text { gram } \\
\text { EXP: } 11 / 06 / 11\end{array}$ & $\begin{array}{l}\text { net weight: } 1 \text { kilogram } \\
\text { EXP: } 29 / 06 / 11\end{array}$ & $\begin{array}{l}\text { net weight: } 65-70 \text { gram } / \mathrm{pc} \text {. } \\
\text { EXP: } 29 / 12 / 10\end{array}$ \\
\hline
\end{tabular}

\section{Actual Round 3}

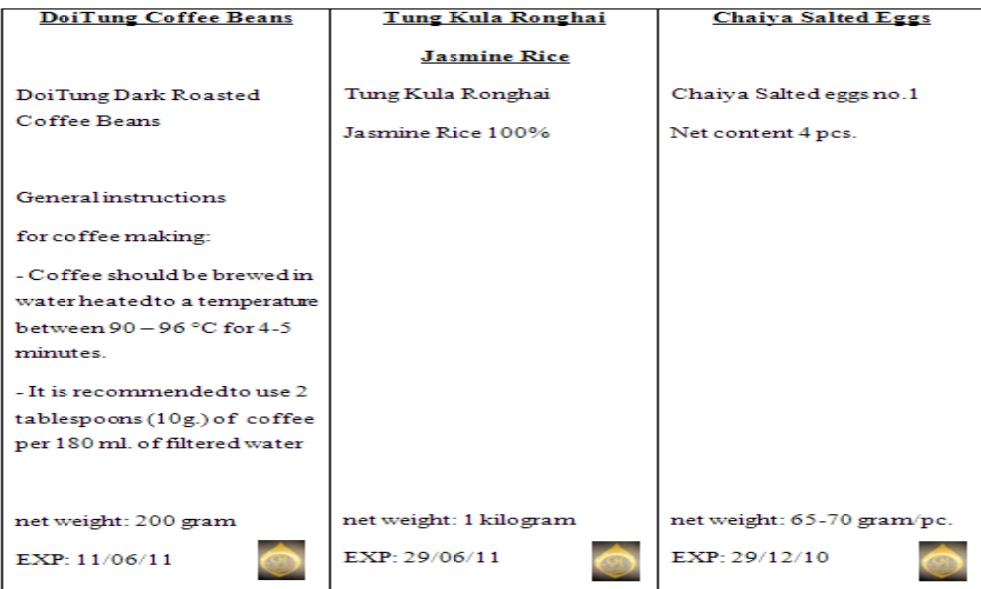

Figure 1. Examples of labels of each product in the experiment

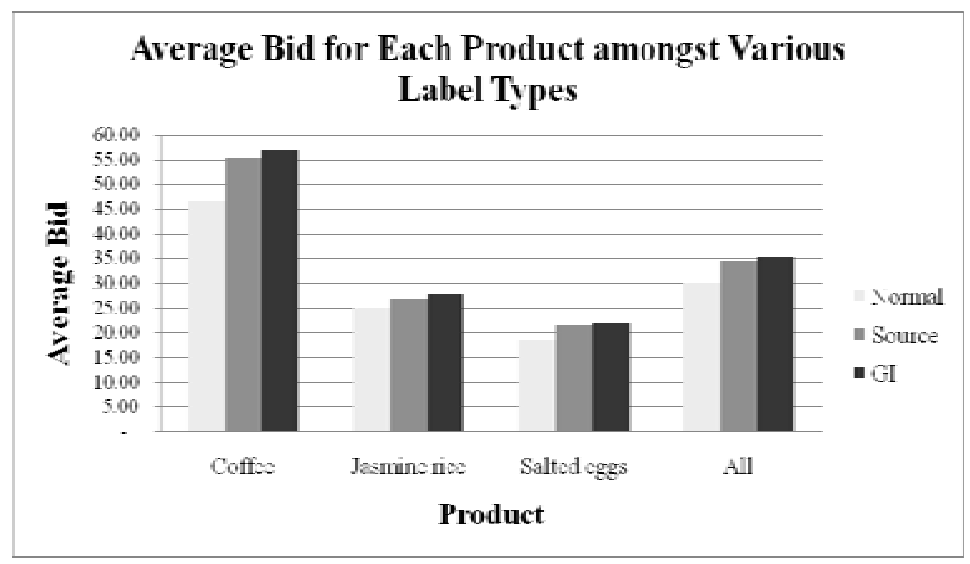

Figure 2. Average bid for each product amongst various label types 